\title{
EXAMINING THE RHETORICAL STRUCTURE AND DISCURSIVE FEATURES OF LETTERS OF LENIENCY AS A GENRE
}

\author{
Marianne Mason
}

\begin{abstract}
This paper presents a genre analysis of 73 letters of leniency, which were obtained in two United States federal district courthouses. The primary objective of this type of genre is to persuade a judge to be lenient during the sentencing of a defendant, such as by reducing or commuting the defendant's sentence. This paper examines how writers of this genre structure their letters and use discursive features, in particular linguistically-realized politeness and appeals to the judges' faith, to make a request for leniency. The findings of this study show that the rhetorical and discursive features of letters of leniency follow the conventions of the court, which demands the observance of the judge's face through the use of politeness. This study also shows how the notion of faith is exploited in this type of genre to make a persuasive request or, more often, to follow-up a request (post-request) for leniency.
\end{abstract}

Keywords: Letters of leniency; Genre analysis; Politeness; Forensic linguistics; Discourse analysis.

\section{Introduction}

What would compel someone to write a letter requesting leniency from a judge? The response lies in the writer's sense of desperation which prompts him or her to write to the judge and ask for mercy before a defendant is sentenced. The defendant is, on most occasions, a close relative or friend of the writer. The purpose that drives those who write this type of discourse, thus, is to persuade a judge to reduce or, preferably, commute the defendant's sentence. The manner in which the writer structures his or her letter and uses language reflects the negotiation between the writer's objectives and the cultural and social conventions of the court. The legal system is, for the most part, hierarchical and conservative. Social boundaries and power structures are clearly defined, and they are inextricably linked to whom has power and whom that power affects (Conley and O'Barr 1998). In the case of a defendant who is awaiting sentencing, the judge may exercise his or her power by deciding the terms and length of a defendant's sentence. The writer, who does not have direct access to the sentencing process or to the judge, in turn, must exercise 'persuasive resistance' to the power of the court system.

Because the writer's status in the exchange is unequal to the judge's, that is, the judge, unlike the writer, is a representative of the court and has the power to sentence the defendant, he or she frames the request observing the "separateness" (Arundale 
2006) between them. The separation between writer and judge, often, may border on the submissive, as illustrated in the following emotive plea:

(1) Your honor, I beg you to have a little compassion for my father on the day of his sentencing.

Writers of this genre persuade by banking on the "intuitive moral appeal" (Hurd 2007: 393) that institutional acts of mercy, such as reducing or commuting the sentence of a defendant, may have on the judge. In letters of leniency, the writer does not use the law to make a compelling argument. These letters are about making a request that has very few possibilities of being considered or granted. The writer simply hopes that the letter appeals to the judge's basic (human) sense of compassion and generosity, which may not be consonant with sentencing guidelines for the defendant's offenses. In letters of leniency, the writer asks a higher authority (of the courts) for mercy and hopes for a positive response.

In this study, I will examine how writers of letters of leniency structure their letters and use language to make a request for leniency to a judge. To accomplish this task, first, I will analyze how letters of leniency, as a genre, are structured and second, I will explore how the discursive features of this genre, specifically the writers' attempts at persuasion through the use of linguistically-realized politeness and appeals to the judges' faith, reflect the effects of distance and separation between parties in the court system. This analysis will contribute to the field of forensic linguistics by applying contemporary politeness theory to a type of discourse that serves a unique purpose in the courts, that is, that requests clemency from a judge, but that has remained an 'unfamiliar' genre (Bhatia 1993). The findings of this study will provide insights into the linguistic structure of letters of leniency, at both a macro and micro level, and the effect of legal power and practice on the discursive strategies of writers of this type of genre.

\section{Method}

The corpus includes 73 letters in which a defendant or his or her loved one requests leniency from a judge. Of these 73 letters, six letters were written by the defendants ( 4 males and 2 females). Of note, the letters, be they written by the defendant or someone else, were examined to establish whether they were significantly different in structure or in the linguistic devices used. The letters share the same rhetorical structure and linguistic devices (e.g., use of politeness). The only difference is that in the letters written by the defendants, the receiver of the judges' actions and the defendant are the same person.

The letters that comprise the corpus are, for the most part, one page in length and typed. Five of the letters were hand-written. The letters were obtained in the summers of 2002 and 2005 from two federal district courthouses located in the southeastern United States that approved my request to perform research on the condition of maintaining confidentiality and not revealing the identity of the writers or defendants. Forty-one of the letters were obtained from one courthouse, and the remaining 32 from another. The letters were randomly selected.

The defendants, of which 83\% are male (61/73), have all been charged and tried for drug offenses, such as the illegal distribution of drugs and/or drug trafficking, and 
were awaiting sentencing at the time the letters were written. Most of the letters were written by relatives, in particular mothers (39/73 or $53 \%$ ), spouses (19/73 or $26 \%$ ), or friends $(9 / 73$ or $12 \%)$ of the defendants. Women account for the majority of the writers (55/73 or $75 \%)$. The main explanation for the larger ratio of female writers to male writers (55 to 18) in the data may be socio-economic; that is, the presence of more single mothers in poorer communities, and more men being convicted of crimes, specifically drug-related crimes, than women in the United States.

The analysis of the data consisted of examining the rhetorical and linguistic devices used in the sample. Each letter was coded to account for structural moves or components (Swales 1990). The letters were also examined to determine how linguistically-realized politeness is used to manage differences in status between writer and judge in various types of moves. The analysis of language use in the data focuses primarily on linguistically-realized politeness, specifically the writers' use of requests. The writers' appeals to the judges' faith, as exemplified in the mention of God to perform various types of requests, are also explored.

Finally, the presence of each structural and micro-linguistic element was catalogued in an Excel file. The structural elements were classified by type of move and the lexico-grammatical components by type of linguistic feature, such as the marker 'please', sentence-initial hedges, pleading verbs (e.g., 'beg'), and directive verbs followed by the term God (e.g., 'ask God'). The purpose of this classification is twofold: first, to establish the total frequency of each rhetorical move and the rate and frequency of each linguistic feature identified in the texts and second, to determine how these features, and the rate in which they are used, provide information about the writers' discursive preferences when requesting leniency. This is important, since it provides insights into the discursive strategies that appear to be used strategically to carry out the writers' main objective of swaying the judge to provide leniency to the defendant during sentencing.

\section{Rhetorical components}

The rhetorical and macro analysis of text discourse has traditionally focused on a movebased analysis (Bazerman 1989; Swales 1981, 1990; Bhatia 1993, 1998, 2004; Biber, Douglas, and Upton 2007). This approach to discourse analysis has been applied to a plethora of professional and institutional discourse whose main purpose is to persuade, such as direct mail letters (Torre and Bendixen 1988; Upton 2002; Connor and Upton 2003), fund-raising letters (Abelen, Redeker, and Thompson 1993), and business letters (Bargiela-Chiappini and Harris 1996; Chakorn 2006). Although letters of leniency do not constitute a type of academic or professional genre, the main purpose of these types of letters, as with other types of request letters, is to persuade. Letters of leniency, thus, lend themselves well to a move-based analysis that describes the rhetorical structure of a genre.

Letters of leniency are composed of moves/components that, in terms of frequency, are used conventionally or not (Kanoksilapatham 2007). The rhetorical structure of these types of letters, hence, includes both compulsory (C) and optional (O) components (Bargiela-Chiappini and Harris 1996; Chakron 2003): 
Salutation

Background information

Pre-Request

Request

Post-Request

Complimentary close and signature
(C)

(O)

(O)

(C)

(O)

(C)

The salutation move refers to an opening address and includes general pleasantries and/or terms of address, such as 'Honorable Judge', 'Your Honor', and 'Your Excellency'. The first two terms are demanded by the speech situation and, hence, expected. The term 'Honorable Judge', for example, is used 36 times in the salutation move, whereas 'Your Honor' is used 14 times. The writers' use of the term 'Your Excellency', however, is somewhat surprising. After 'Honorable Judge', the term 'Your Excellency' is the most commonly used term of address in the data. This move is observed 23 times. Although it is speculative at this point, it is possible that the writers of these types of letters perceive the term 'Your Excellency' as more deferential than terms such as 'Your Honor', which may explain its frequent occurrence in the corpus.

The body of the letter includes compulsory components, such as request moves, and optional ones, such as background information, pre-request, and post-request moves. The main purpose of the background information move, for example, is to provide information about the defendant's character that helps cast him or her in a good light:

(2) I would like to attest to the virtues and the high caliber of the personal qualities that my daughter possesses. She is a hard worker and a good mother and daughter. She has never been in trouble before this time.

This move may also provide information about the case, particularly to stress some sort of injustice, and/or suggest the presence of extenuating circumstances, such as being "tricked" by co-defendants:

(3) I have been a victim in this case because I was a mule. But I was a blind mule because I never knew what I was carrying. I am an honest and hard-working person.

The pre-request move signals that a request is to follow. In this sense, and applying principles of conversation analysis, in particular Schegloff's (1990), to the analysis of written discourse, a pre-request alerts the judge of an upcoming request such as:

(4) I have decided to appeal to you this way.

(5) I feel compelled to impose on you.

(6) I am very concerned about how the sentence will affect his children, which is why I am contacting you.

Pre-requests, thus, function to prepare the judge for a dispreferred move, or the request for action, which imposes on him or her. judge:

The request move, on the other hand, is aimed at obtaining a response from the 
In letters of leniency, the writer wants the judge to respond to his or her request in one of two ways: give the defendant a reduced sentence (preferred) or commute the defendant's sentence (most preferred).

Post-requests consist of expansions of the core requests. They are closing remarks that normally appear at the end of a letter, prior to the complimentary/close and signature, and which express anticipation and/or appreciation to the reader:

(8) I thank you for your attention and for being kind enough to want to help human beings in a fair manner.

In letters of leniency, post-requests also often include the use of phrases, such as 'may God bless you' that may appeal to the judges' faith and beliefs. Some examples of postrequests taken from the data include:

(9) Anticipating your attention in this matter, I thank you gratefully. May God bless you.

(10) I anticipate your attention in advance and your help if it were possible for you. Again, I apologize for my boldness. May God guide you.

The final move of a letter of leniency is the complimentary close and signature. The complimentary close may include terms that are traditionally used in professional letters, such as respectfully, sincerely, and cordially.

Table 1 illustrates the rate of usage of each move in the data, and the most common order/positioning of the moves in the genre:

Table 1

Move Frequencies and Rates of Occurrence

\begin{tabular}{llllll}
\hline Type of Move & \multicolumn{2}{l}{ Moves } & \multicolumn{2}{l}{ Letters } & Words/move \\
& Total & $\%$ of Total & Total & $\%$ of Total & Average \\
Salutation & 73 & $18 \%$ & 73 & $100 \%$ & 2 \\
Background & 66 & $16 \%$ & 66 & $90 \%$ & 65 \\
Pre-Request & 57 & $14 \%$ & 53 & $73 \%$ & 10 \\
Request & 73 & $18 \%$ & 73 & $100 \%$ & 23 \\
Post-Request & 69 & $17 \%$ & 69 & $95 \%$ & 9 \\
Complimentary & 73 & $18 \%$ & 73 & $100 \%$ & 1 \\
\hline Close/Signature & $73 \%$ & & & \\
\hline
\end{tabular}


The data is comprised of 411 moves. Those moves that are compulsory occur in all 73 letters. The 'total' line indicates each time a type of move occurs in the corpus. Compulsory moves only occur once in a letter. Optional moves, with the exception of pre-requests which occur four times before and after the background move, are also observed only once in the letters in which they occur. Of note is that post-requests (69/73 or 95\%) and background moves (66/73 or 90\%) occur in almost all the letters that comprise the corpus making these moves quasi-compulsory.

In addition, the order in which the moves occur does not necessarily agree with paragraph number or order. The background move, for example, may take two or, in longer letters, three paragraphs to complete. On 10 occasions, pre-requests occur embedded in the request move. There is also some flexibility in move-structure order. Requests, for example, occur before the background information move on four occasions. In these cases, the background move is followed by a post-request. Finally, pre-requests do not necessarily have to appear after the background move, but they always precede core requests.

In the next section, I will analyze the linguistic devices used to persuade and manage the potential threats to the judges' face in letters of leniency. The examination will focus on the writers' use of linguistic politeness in core and, to some extent, post requests. These moves were chosen because they carry the writers' requests and, thus, show most poignantly the mechanisms writers of this genre use to persuade judges whose social and professional status in the exchange is higher than the writers'.

\section{Linguistically-realized politeness in letters of leniency}

The most widely applied, and critiqued, approach to the study of face, as related to politeness, is the one proposed by Brown and Levinson (1987). Inspired by Goffman's (1976) notion of face, or the image that a person projects in the social contacts with others, Brown and Levinson argue that face is constantly at risk, since any type of linguistic action could be construed as a face-threatening act or FTA. The threat to face could interfere with two separate types of human wants: positive face and negative face. Goffman defined the need to be appreciated positive face and the need not to be interfered with negative face. In Brown and Levinson's theory, any act that threatens an individual's positive or negative face must be counterbalanced with linguisticallyrealized politeness.

For example, Brown and Levinson propose that the intensity of the threat to face is expressed by the sum of three social values: the rate of imposition, the social distance between the speaker and the addressee, and the relative power between them. In this approach to politeness, the form of redress to correct a threat to face is contingent on the seriousness of the FTA. That is, the higher the value, as for example the more distance between speaker and addressee, the more polite the strategy needs to be. In Brown and Levinson's model, politeness is a redressive and strategic device whose main function is to maximize the benefit to self and the other (positive politeness) and avoid conflict (negative politeness). Although Brown and Levinson's theory has been applied mostly to spoken discourse, at present this theory has been widely used to analyze face and linguistically-realized politeness in written discourse, such as persuasive texts (see Pilegaard 1997; Bargiela-Chiappini and Harris 1996; Chakorn 2006; Anthony and Gladkov 2007). 
Nonetheless, despite the widespread application of Brown and Levinson's theory to the analysis of both oral and written discourse, this theory has been critiqued by several researchers on the grounds that it has limited cross-cultural applicability (Ide 1989; Kasper 1990; de Kadt 1998; Haugh 2003, 2005), and it does not examine the conceptualization of face as an interpersonal and socio-cultural phenomenon (Arundale 1999, 2006; Bargiela-Chiappini 2003; Christie 2004).

Most of the critique of Brown and Levinson's view of the universality of face has come from researchers who study non-Western cultures, in particular Chinese (Gu 1990; Mao 1994; Ji 2000) and Japanese (Ide 1989). Kasper (1990: 196), for example, notes that social-indexing is an essential component of linguistically-realized politeness, which is culture-specific. In some non-Western societies, such as Japan, social-indexing and "discernment" (Ide 1989: 132) shape politeness strategies, such as the use of honorifics, rather than volition. The notion of volition or "strategic politeness" (Kasper 1990) assumes that considerations of cost and benefits influence a speaker's choice of a polite form rather than obligation. The view that volition, rather than cultural demands shape the discursive features of a speech-context is problematic not only for cultures in which social indexing is the motivating force behind politeness, but also in multiple oral and written discourse contexts in which cultural demands shape the speech situation. Politeness, as Haugh (2003: 399) notes, "...is a culture-sensitive phenomenon".

An alternative, but complimentary, view of face that also addresses the criticisms of Brown and Levinson's theory examines positive and negative face as a relational rather than individual phenomenon (Arundale 1999, 2006; Bargiela-Chiapini 2003). Bargiela-Chiapini, for example, proposes "the need to understand and compare cultural conceptualizations of the social self and its relationship to others as an alternative and possibly more fruitful way of studying the relevance and dynamics of face and face-work in interpersonal contacts" (2003: 1463). This re-conceptualization of face is further explored in Arundale (2006). He suggests that positive and negative face are best addressed as the dialectical opposition between connection and separation from others:

\footnotetext{
...connectedness and separateness provides a clear, culture-general conceptualization of "positive" and "negative" face.... As a re-conceptualization of positive face, "connection face" encompasses a range of interpretings much broader than, but inclusive of being "ratified, understood, approved of, liked or admired" by others (Brown and Levinson 1987: 62). As a re-conceptualization of negative face, "separation face" encompasses meanings and actions that include among many others, a person's "freedom of action and freedom from imposition" or "claim to territories" (2006: 204-205).
}

Arundale's approach to face provides a culture-general conceptualization that can be adapted to the analysis of written discourse in a variety of cultures and settings, such as the court system. Because the court system has a clearly defined social order that shapes the relationships of peers and non-peers, as for example judges, defendants, and writers of letters of leniency, it sets boundaries between them. In this sense, the writer's use of politeness reflects his or her understanding of where he or she belongs (inclusion) and stands (distinctions). These principles which are not universal, but rather "...culture-specific manifestations of more abstract notions, namely connectedness and separateness respectively" (Haugh 2005: 63) provide a mechanism to analyze face management in letters of leniency. The writer's use of politeness in this type of genre reflects his or her place in the exchange, which is 'assigned' by the court system. That is, 
for those who write letters of leniency there is no other (rational) option but to defer to the judge who has a higher status and power in the exchange. The writers' separateness from the judges is, thus, a driving force in the discursive features they employ, specifically types of requests, to achieve linguistically-realized politeness in the corpus.

\subsection{Making requests: Performing politeness in letters of leniency}

Requests are situated in contexts of social relations and of activity, and their form and interpretation depend on them. The culture of the courtroom engenders separateness between a judge, the defendant, and the writer of a letter of leniency who, often, is writing on behalf of the defendant. In the data, separateness is observed in the types of requests made. The writers perform requests using the following linguistic mechanisms: 1) please + directive verb (e.g., 'help' and 'give'), 2) hedged requests ('with all due respect' + directive verb), 3) pleading verbs 'beg' and 'pray' + phrase or clause, 4) directive verb 'ask' + 'God' (i.e., request is intended for the judge, but oriented to a higher authority). Table 2 illustrates the distribution of request types (i.e., core-requests) in the data:

Table 2

Distribution of Request Types in the Data

\begin{tabular}{lll}
\hline Request Type & $\begin{array}{l}\text { Distribution } \\
\text { Total }\end{array}$ & $\%$ of Total \\
Please + Verb & 12 & $16 \%$ \\
Hedge + Verb & 8 & $11 \%$ \\
Beg + Phrase/Clause & 21 & $29 \%$ \\
Pray + Phrase/Clause & 29 & $40 \%$ \\
Ask + God & 3 & $4 \%$ \\
\hline
\end{tabular}

As Table 2 shows, the most common request-types in letters of leniency are realized using pleading verbs or verbs that request assistance, such as 'please + directive verb'. Other less common request strategies, but which stand out, include invoking God.

\subsubsection{Please + directive verb}

Writers of letters of leniency use imperatives headed by 'please' to perform requests. In letters of leniency, the linguistic realization of requests that are in the imperative mood is an infinitive verb, specifically 'consider', 'help' and 'give', preceded by 'please':

(11) Please consider my husband's problems before you sentence him.

(12) Please help my son see his children again. 
The use of an imperative headed by 'please' appears to be intimately connected with the speech act 'request', and, hence, explains why 'please' is used in letters of leniency to indicate"...the utterance with which it co-occurs as a request for action" (Sato 2008: 1252). The request that follows 'please', and which may be anticipated by the context, imposes on the judge, since it requests from him or her a course of action that may not be granted given the sentencing guidelines available for the types of crimes the defendant has been charged with and tried for, such as drug-related convictions.

The use of 'please' as a face-saving device is also enhanced by its position in the phrase or clause, which seems to play a role in assigning functional characteristics to the foregoing discourse. In examples 11 and 12, as in 98\% of the instances in which 'please' occurs in the data, it occurs in clause-initial position. The occurrence of clauseinitial 'please' in imperatives shows the writers' sense of “...situational urgency and/or his/her sense of desperateness" (Sato 2008: 1260), which, in turn, reflects the writers' position of disadvantage (powerlessness) in the exchange. Writers in the genre are desperate because the judge is the ultimate authority in the defendant's case and, thus, he or she will decide the short or, given the charges against the defendant, long-term future of the defendant.

\subsubsection{Hedged requests}

One of the linguistic devices that writers in letters of leniency use to manage the judges' face is the phrase, 'with all due respect', to initiate a request. This phrase, similarly to 'please', frames the foregoing request within the situation-specific social norms of the context:

(13) With all due respect, I ask you to consider my son's circumstances when deciding his sentence.

(14) With all due respect, I ask you Your Honor for a reduction in my niece's sentence.

In examples 13 and 14, the writers are making a request to the judges, from their own perspective: 'I ask you to consider X". The writers recognize that the culture of the court demands that differences in status between writer and judge be recognized. Thus, judges may interpret a request that is initiated with the verb 'ask', as for example 'I ask that you do $\mathrm{X}$ ' without a hedge, such as 'with all due respect', as a violation of the separation between writer and judge. This explains, in part, why all requests that use the verb 'ask' in the data are preceded by a hedge and often followed by a term of address, such as 'Your Honor.' Hedging a directive verb, such as 'ask', is consonant with the notion of separateness that frames exchanges between those who request leniency for a defendant, and the judge who has the power to grant such a request. 


\subsubsection{Pleading verbs pray and beg}

In letters of leniency, unlike traditional letters of request, writers may employ persuasion through the use of pleading verbs, such as 'pray' and 'beg', combined with phrases/clauses, such as 'that you have mercy', that persuade the judges through emotional appeals. Because the judge has the ultimate authority to decide a defendant's sentence, and, thus, what the defendant can or cannot do in the future, these types of verbs 'fit' the context of the appeal; that is, they give the writers license to plea, which explains their frequent usage in the data (68\% of all requests types):

(15) I beg you, Your Honor, to be charitable with my daughter.

(16) I pray that you be lenient with my mother.

(17) I beg you for mercy when you make the decision as to my husband's sentence.

Pleading verbs reflect the writers' willingness to plea to the point of showing subservience in order to achieve the desired response from the judges. The writers' use of verbs with such emotional baggage as 'pray' and 'beg' reflect acutely the writers' perception of the judges' power and status in the exchange. In a sense, the writers plea because the judges' power is akin to God's, albeit in the judicial realm. The writers are willing to set their pride aside and defer to the judges so as to obtain a response that results in the reduction of the defendants' sentence. Of note, I will add that female writers employed more frequently than their male counterparts pleading verbs, specifically 'beg' (18/21 or $86 \%$ ), when addressing the judges. Because writers of this genre do not routinely engage with each other to carry out this particular communicative event, the writers do not constitute a "community of practice" (Eckert and McConnellGinet 1992). Furthermore, very little is known at this point about this type of genre, hence, I could only speculate as to why female writers employ this tactic more frequently.

In keeping with the notion that how writers of letters of leniency 'locate' (Mills 2004) themselves in the exchange shapes their language use, it seems plausible that female writers of this sample use requests such as 'beg' and 'pray', because they play a role in the maintenance of status and class distinctions. One of the sociolinguistic variables that appears to be shared among those who write letters of leniency is their socio-economic background. As I noted in the method section, most of those who write letters of leniency are mothers and wives of the defendants. The defendants, of which 83\% are male (61/73), were all charged and convicted for drug offenses, such as the illegal distribution of drugs and/or drug trafficking. The type of crime committed, which in the United States is often correlated with poorer communities, suggests that most, if not all, of the women who wrote the letters in the corpus perceive themselves to be in a position of social and financial disadvantage. For female writers in the corpus, unlike their male counterparts who did not use pleading verbs as frequently, this perception of disadvantage appears to be a guiding force in how they frame requests. It is not uncommon in the background move of the data, for example, to find female writers making brief reference to how the conviction of their loved one will be very burdensome for them: 
(18) I am a 70-year-old woman who must work to support my family. I am responsible for my grandson now which is very difficult for me. I do not have a pension and I have many problems.

The use of pleading verbs in the data, hence, may reflect how female writers externalize their class and gender in their management of face and in their use of linguistic politeness when addressing judges. Future research, however, with a larger and more diverse data set is needed to provide further insights into the use of genderedspeech patterns in letters of leniency.

\subsubsection{Directive verbs + God}

One of the most interesting linguistic devices writers in the study use to perform requests is to phrase the request in a manner that is intended for the judge, but directed to a higher authority:

(19) I ask God that his offense not be punished too severely, since each and everyone of us has made a mistake and has the right to a second chance.

(20) God showed compassion towards all of us giving his only son to die for us. I pray to God that my nephew receives a short sentence.

These types of requests, which were observed in only three occasions, seem to appeal to the judges' ethical compass when making judgments. That is, the writers remind the judges of God's mercy in the hope of obtaining a response from the judges that observes basic human values, such as showing compassion for others. Since the writers are appealing to the judges', possible, moral and human values, and they are not directly instructing them to respond in a certain way - God is invoked to mediate that - the request constitutes an indirect request. That is, the illocutionary force (Grice 1975) of these types of request is implied in the writers' use of God to 'tell' the judges what the "correct" course of action should be when sentencing the defendants.

The writers' mention of God in these requests, which falls outside of the writers' typical request strategy, seems to constrain the decision-making abilities of the judges. That is, the writers still recognize differences in status with the judges, hence the use of an indirect request, but by bringing God into these types of requests the writers are no longer recognizing the judges' ultimate authority on all plains: heaven and the courts. In this request style, unlike those discussed in prior sections, although the writers have less power than both God (in all realms) and the judges (in the courts), both the writers and the judges have less power than God.

\section{The role of post-requests: Making reference to a higher authority}

In letters of leniency, writers may also use God not to make a core request, but to show anticipation and/or appreciation to the judges for responding to the request. This rhetorical move, or post-request, is the writers' last attempt to show the judges that the imposition the letter may cause on their person is not only greatly appreciated by the writers, 'I thank you in advance for reading this letter', but also potentially recognized 
and rewarded by God. In the corpus, post-requests often include the use of sentences in the subjunctive mood that mention God (52/69 or 75\%), as illustrated in examples 21 and 22:

(21) Honorable Judge, I thank you for your help with this problem and may God bless you for helping my son.

(22) May God reward you for whatever you can do for my daughter, and receive my greetings and appreciation.

This type of strategy that employs God to construct spirituality in a plane outside, and 'above', the court system, in particular, is not observed in typical request letters and appears to be fairly unique to the genre. Referencing God or a higher authority, however, is a persuasive tool used in religious contexts and constitutes a speech act. As Bruder (1998: 470) notes "...we may regard the blessing as an essentially religious act implying the existence and activity of a Transcendent, yet imminent. Being whose favor is being requested in the speech act itself."

In letters of leniency, the writers promote the notion that to receive God's blessings and be rewarded one must be charitable and show compassion for others. The speech act of blessing, hence, stems from the writers expressing a 'wish' (Bruder 1998: 470) for God to bless the judges in the discourse exchange. The writer does not have the power to grant a favor, but he or she may act as a human agent for the invocation of a blessing on behalf of another. By soliciting from God a blessing, those who subscribe to the belief of a higher being may benefit.

In essence, post requests allow the writers to show appreciation towards the judges for having to read the letter, through the use of an intermediary, or God, who may bestow positive rewards (i.e., a blessing that will have observable, natural consequences), for reducing or commuting a defendant's sentence. This strategy, hence, counts on the apparent moral and spiritual appeal of institutional acts of mercy to which the writers hope the judges respond.

\section{Conclusions}

In this study, I have presented a summary of the genre structure and politeness strategies used in 73 letters of leniency, which were obtained in two United States federal district courthouses. The analysis of this genre reveals that the writers of these letters, for the most part, are affected by social and cultural factors, such as differences in status between writer and judge, that shape how the writers perform requests, specifically how they incorporate politeness and issues of faith in their use of directives. In letters of leniency, unlike other more traditional persuasive genres, a linguistic feature that stands out is the writers' formulation of requests with verbs such as 'beg' and 'pray'. The writers may also invoke God in their requests to ask the judges indirectly to do what is ultimately 'correct'; that is, to do God's will on earth, or to show the judge that God rewards those who show compassion for others.

Gender differences in the treatment of politeness in request moves were also an interesting finding of this study. Although it is important to note that these differences were observed in a limited capacity, they appear to be in keeping with the notion that the manner in which writers 'locate' themselves in the exchange may shape their 
language use. This study suggests that female writers' use of requests, specifically 'beg', may play a role in the maintenance of status and class distinctions between female writers and the judges in letters of leniency.

In sum, this study provides an initial view of how letters of leniency are structured and discursive features, such as linguistic politeness and speech acts that invoke God, are realized. Since this analysis is a first attempt at examining the linguistic and discursive features of letters of leniency, future research, with a larger and more diverse sample, is needed to further our understanding of this genre. Areas of future research, for example, may include: the examination of the apparent uniformity of the rhetorical structure and discursive features of letters of leniency (i.e., the possible influence of third parties, such as attorneys), the similarities between letters written by those on behalf of the defendant and the defendant, and the, possible, relationship between gender and socio-economic variables in shaping language use in legal settings.

\section{References}

Anthony, M., and K. Gladkov (2007) Rhetorical appeals in fundraising. In D. Biber, U. Connor \& T.A. Upton (eds.), Discourse on the move using corpus analysis to describe discourse structure. Amsterdam: John Benjamins Publishing Company, pp. 121-51.

Arundale, R.B. (1999) An alternative model and ideology of communication for an alternative to politeness theory. Pragmatics 9.1: 119-53.

Arundale, R.B. (2006) Face as relational and interactional: A communication framework for research in face, facework, and politeness. Journal of Politeness Research 2: 193-216.

Abelen, E., G. Redeker, and S.A. Thompson (1993) The rhetorical structure of US-American and Dutch fund-raising letters. Text 13.3: 323-50.

Bargiela-Chiappini, F. (2003) Face and politeness: New (insights) for old (concepts). Journal of Pragmatics 35: 1453-69.

Bargiela-Chiappini, F., and S.J. Harris (1996) Requests and status in business correspondence. Journal of Pragmatics 28: 635-62.

Bazerman, C. (1989) Shaping Written Knowledge. Madison, WI: University of Wisconsin Press.

Bhatia, V.K. (1993) Analysing Genre: Language Use in Professional Settings. London: Longman.

Bhatia, V.K. (1998) Generic patterns in fundraising discourse. New Directions for Philanthropic Fundraising 22: 95-110.

Bhatia, V.K. (2004) Worlds of Written Discourse. London: Continuum.

Biber, D. (1988) Variation Across Speech and Writing. Cambridge: Cambridge University Press.

Biber, D., U. Connor, and T.A. Upton (2007) Discourse on the Move Using Corpus Analysis to Describe Discourse Structure. Amsterdam: John Benjamins Publishing Company.

Brown, P., and S. Levinson (1987) Politeness: Some Universals in Language Usage. Cambridge: Cambridge University Press. 


\section{Marianne Mason}

Bruder, K.A. (1998) A pragmatics for human relationships with the divine: An examination of the monastic blessing sequence. Journal of Pragmatics 29: 463-91.

Chakorn, O. (2006) Persuasive and politeness strategies in cross-cultural letters of request in the Thai business context. Journal of Asian Pacific Communication 16.1: 106-46.

Christie, C. (2004) Introduction. Multilingual 23.1: 1-11.

Conley, J.M., and W. O’Barr (1998) Just Words: Law, Language, and Power. Chicago: University of Chicago Press.

Connor, U., and T.A. Upton (2003) Linguistic dimensions of direct mail letters. In C. Meyer \& P. Leistyna (eds.), Corpus analysis: Language structure and language use. Amsterdam: Rodopi, pp. 71-87.

Eckert, P., and S. McConnell-Ginet (1992) Think practically and look locally: Language and gender as community-based practice. Annual Review of Anthropology 21: 461-90.

Goffman, E. (1967) On face-work: An analysis of ritual elements in social interaction. In E. Goffman (ed.), Interaction ritual: Essays in face-to-face behavior. Chicago: Aldine, pp. 5-45.

Grice, H.P. (1975) Logic and conversation. In P. Cole \& J.L. Morgan (eds.), Syntax and semantics, vol 3: Speech Acts. New York: Academic Press, pp. 41-58.

Gu, Y. (1990) Politeness phenomena in modern Chinese. Journal of Pragmatics 14: 237-57.

Haugh, M. (2003) Anticipated versus inferred politeness. Multilingua 22: 397-413.

Haugh, M. (2005) The importance of 'place' in Japanese politeness: Implications for cross-cultural and intercultural analyses. Intercultural Pragmatics 2.1: 41-68.

Hurd, H.M. (2007) The morality of mercy. Ohio State Journal of Criminal Law 4: 388-421.

Ide, S. (1989) Formal forms of discernment: Two neglected aspects of linguistic politeness. Multilingua 8: 223-48.

Ji, S. (2000) 'Face' and polite verbal behaviors in Chinese culture. Journal of Pragmatics 32: 1059-62.

de Kadt, E. (1998) The concept of face and it's applicability in the Zulu language. Journal of Pragmatics 29: 173-91.

Kanoksilapatham, B. (2007) Introduction to move analysis. In D. Biber, U. Connor, \& T.A. Upton (eds.), Discourse on the Move Using Corpus Analysis to Describe Discourse Structure. Amsterdam: John Benjamins Publishing Company, pp. 23-41.

Kasper, G. (1990) Linguistic politeness: Current research issues. Journal of Pragmatics 14: 193-218.

Mao, L.R. (1994) Beyond politeness theory: 'Face' revisited and renewed. Journal of Pragmatics 21: 45186.

Mills, S. (2004) Class, gender and politeness. Multilingua 23: 171-90.

Sato, S. (2008) Use of "please" in American and New Zealand English. Journal of Pragmatics 40: 124978.

Schegloff, E. (1990) The organization of sequences as a source of coherence in talk-in-interaction. In B. Dorval (ed.), Conversational organization and its development. Norwood, N.J.: Ablex, pp. 51-77.

Swales, J.M. (1981) Aspects of Article Introductions. Aston University: Language Studies Unit. 
Swales, J.M. (1990) Genre Analysis: English in Academic and Research Settings. Cambridge: Cambridge University Press.

Torre, L., and M.A. Bendixen (1988) Direct Mail Fund Raising: Letters that Work. New York: Plenum Press.

Upton, T.A. (2002) Understanding direct mail letters as a genre. Journal of Corpus Linguistics 7.1: 65-85.

MARIANNE MASON is a faculty member at Georgia State University. Her areas of expertise include forensic linguistics, discourse/genre analysis, pragmatics, and translation/interpreting theory. She has published in the fields of forensic linguistics and discourse analysis in the Journal of Pragmatics, Police Quarterly, and Pragmatics.

Address: Georgia State University, Atlanta, GA 30324, United States. E-mail: mmason14@gsu.edu 